This manuscript is a preprint and has been submitted to the Journal of Hydrology. Please note that this manuscript is undergoing peer-review and has not been accepted for publication. Subsequent versions of this manuscript may have slightly different content. If accepted, the final version of this manuscript will be available via the 'Peer-reviewed Publication DOI' link on this web page's right-hand side. Please feel free to contact the corresponding author. We appreciate your feedback. 


\title{
Evaluating Real-time Control Performance on System-level Urban Flooding Reduction and Water Quality Improvement
}

\author{
Jiada $\mathrm{Li}^{\mathrm{a}, *}$, Carlos Oroza ${ }^{\mathrm{a}}$, Steven Burian ${ }^{\mathrm{a}}$ \\ aDepartment of Civil and Environmental Engineering, University of Utah, 201 Presidents Circle, \\ Salt Lake City, UT, USA \\ a,* Corresponding author, email: jiada.li@utah.edu
}

\section{Highlights}

1. Individual local control reduces flooding stress most at the downstream outlet.

2. System-level control outperforms individual control in co-benefiting water quantity and quality.

3. The system-level controller performance relates to storage ponds' size and location.

4. Outflow of storage units is an essential signal of temporal changes in orifice openings.

\begin{abstract}
Increases in the application of smart technology and data analytics enable urban drainage engineers to retrofit the stormwater storage facilities with controllers, such as valves and gates, to address flooding and water quality problems. This process becomes increasingly challenging because simultaneously controlling the spatially distributed storage assets across the entire watershed is a system-level load-balancing operation. To that end, this study presents a system-level real-time control simulation for assessing the performance of controllers in the tradeoff between flooding mitigation at downstream nodes and water quality improvements at the upstream storage units. An open-source tool called PySWMM is used to conduct step-wise control
\end{abstract}


simulation and water quantity and quality modeling. By simulating three real-time control strategies based on a benchmark, real-world stormwater collection system, we obtain results showing that the system-level control can synchronously maintain multiple-objectives, including reducing peak water depth, shortening flooding duration, and removing pollutants, at the desirable level. In contrast, individual control provides the most favorable performance in mitigating floods at the downstream outlet. In this controlled watershed, the outflow of storage units is examined to be an important predictor for the changes in orifice opening during the co-simulation work. We also find that the size and location of storage units relate to the controller performance, which is promising to design an optimal storage control system for attenuating water quantity and quality over-loadings. All codes for implementing the system-level control strategies are publicly accessible (https://github.com/Jiadalee/PyRTC) to leverage open-source smart real-time control to adaptive stormwater management.

Keywords: Smart stormwater; System-level control; Downstream flooding; Total suspended solids; SWMM and Python

\section{Introduction}

Recently, climate change and anthropogenic activities are drastically challenging stormwater management practices by increasing the magnitude, frequency, and duration of extreme rainfall events. Such climate-related phenomena eventually trigger stormwater problems, namely, flashier hydrographs and pollutographs in the urbanized watershed (Waters et al., 2003). Additionally, urban stormwater has serious effects on UDSs (Urban Drainage Systems) by causing urban drainage flooding, water quality deterioration, infrastructure erosion, and ecosystem impairment 
(Schmitt et al., 2004), and consequently increase economic costs. In 2015 alone, 178 million people around the world were affected by urban floods, and the total economic losses exceeded US\$40 billion (Stevens, 2012). Therefore, it is of great importance to rehabilitate the existing UDSs to address the unexpected challenges on water quantity and quality.

However, most UDSs, with limited conveyance capacity, are not adaptively designed to cope with such rapid water quantity and quality changes (Berggren et al., 2012). Traditionally, engineers tackle stormwater issues by enlarging existing stormwater facilities or re-sizing physical structures in the stormwater infrastructure systems. Nevertheless, upgrades on structural infrastructures are costly for in-site construction (Casal-Campos et al., 2015). The disadvantages of stormwater structure rehabilitation are the adverse impacts on the receiving environment, such as loss of open space and permeable land ( $\mathrm{Li}$ et al., 2019b). In order to minimize these effects, stormwater stakeholders are constantly looking for more dynamic stormwater solutions. One such alternative is the non-structural RTC (Real-Time Control), which has been extensively explored for lessening water quality stress and mitigating flooding severity (Bilodeau et al., 2018; Giordano et al., 2014; Mollerup et al., 2017; Parolari et al., 2018).

Prior studies have considered RTC as an adaptive, efficient, and low-cost practice for optimizing the operational efficiency in water distribution systems (Abou Rjeily et al., 2018; Creaco et al., 2019), adapting drainage systems to changing conditions (Campisano et al., 2013; Löwe et al., 2016; Lund et al., 2019), and improving water quality in ecosystems (Zhang et al., 2018). With interest in non-traditional stormwater management approaches, practitioners have utilized RTC for a range of purposes such as combined sewer overflow reduction, flooding mitigation, 
greenhouse gas emissions control, energy-saving, and TSS (Total Suspended Solids) removal (Chiang and Willems, 2015; Kroll et al., 2018; Li et al., 2020; Muschalla et al., 2014; Ruggaber et al., 2007). Recent studies formulate the control rules to improve TSS removal efficiency from $41 \%$ to $89 \%$ (Sharior et al., 2019), to retain the urban water cycle (Sun et al., 2020), and to reduce combined sewer overflow volume by up to $50 \%$ (Vezzaro and Grum, 2014). Most of the current RTC is based on individual local control, which does not consider system-wide operations (Li et al., 2019a). Individual control is easy-to-implement and simple-to-operate, which has been proven to bring many benefits, including reductions in flooding volume and pollutant loads, to the targeting individual local-site (Sadler et al., 2020). However, the research on answering this question: can doing the best at a local scale achieve the best outcome at the watershed scale is limited (Mullapudi et al., 2017). Although individual site-scale control appears promising, the outcomes might be questionable when the study scale is expanded from the catchment-scale to the watershed-level case studies due to the spatial variabilities of rainfall and spatial changes in land cover (Heusch and Ostrowski, 2015; Kerkez et al., 2016). For instance, the optimal performance at individual storage basin might not necessarily cause an favorable ourcome at system-level multiple basins. The reason for this can be the situation where the control of upstream storage units to attenuate local pollutant over-loadings or overflow is likely to trigger flooding issues at downstream storage assets.

Previous researches have proposed to promote the advancements of system-wide RTC by building broad participation and collaboration among engineers and researchers who may be unfamiliar with the field of stormwater systems; however, whose expertise in controls and optimization may contribute to smart stormwater RTC (Rimer et al., 2019). In practice, recent studies show that 
developing an open-source wrapper connected with the SWMM (Storm Water Management Model) is beneficial for fully considering hydraulic dynamics in real UDSs and site-oriented control logics (Riaño-Briceño et al., 2016; Sadler et al., 2019). Despite the progress in open-source tools for simulating system-level RTC for hydraulic benefits like peak flow and depth reduction, control of the UDSs for system-wide water quality objective is challenging, and only a few studies have assessed the RTC performance on water quality improvements (Meng et al., 2020; Muschalla et al., 2014; Sharior et al., 2019; Troutman et al., 2020). There is still much room open for systemlevel water quality control across the entire watershed.

The objective of this study is to fill in this gap above by assessing RTC performance in achieving system-wide water quality improvements and flooding mitigation at the entire system. A benchmark, real-world watershed-scale urban drainage system located in Southeastern Michigan, U.S., is selected as the case study. The contributions of this study can be summarized as follows:

1) Developing an open-source approach, released at https://github.com/Jiadalee/PyRTC, to formulate and implement the rule-based control logics, creating opportunities for broader participation and contribution to smart stormwater systems;

2) Filling in the gap of connecting step-wise system-level RTC simulation and water quality modeling through the PySWMM tool;

3) Building an index-oriented assessment of RTC performance towards the trade-off between reducing the downstream flooding duration and upstream TSS pollutant amount.

\section{Case study and model}


The case study accepted for this paper is the scenario gamma model of the pystorms package (Rimer et al., 2019). Pystorms package is an open-source benchmarking framework to make smart stormwater network control problems accessible to control experts and promote the growth of a broader community with the easy cross-comparison of control strategy performances. Fig.1a presents the scenario gamma stormwater model, which includes 19 sub-catchments, 10 junctions, 1 outlet, 11 conduits, 11 orifices, and 11 storage units. The case study has an area of $0.8 \mathrm{~km}^{2}$ with an imperviousness of more than $80 \%$. The catchment comprised of 11 storage assets ranges in volume from $5 \mathrm{~m}^{3}$ to $8760 \mathrm{~m}^{3}$ (Fig.1b). Most of the upstream storage units have a small volume capacity, while most of the downstream storage units have a large size. This case study is practically located in the southeastern Michigan state, USA (Fig.1c). The land types of this district include residential areas with $15 \%$ of the total area, commercial areas with $55 \%$ of total area, and industrial areas with $30 \%$ of the total area. Gamma model is chosen because of the distribution of watershed-scale storage units with limited low baseflow and subsequent groundwater effects. The need to reduce downstream flooding, to improve system water quality, and to avoid local overflow offers additional motivations for exploring the benefits of RTC strategy in the case study (HRWC, 2013). This retrofitted urban watershed will serve as a real-world testbed for the modeling outcomes in this paper. At the current stage, this catchment has ongoing efforts to reduce pollutants and alleviate flooding conditions. More information regarding the scenario gamma model and the pystorms package can be found in open-storm.org/pystorms (Rimer et al., 2019).

Pystorms are dependent on PySWMM, a Python wrapper for the creation, manipulation, and study of the structure, dynamics, and function of the popular U.S. Environmental Protection Agency Stormwater Management Model (SWMM) model (Rossman, 2015), to run and dynamically 
control a sewer model throughout a simulation (McDonnell et al., 2020). PySWMM can be used to streamline stormwater modeling optimization and control-processing, which enables control algorithms to be developed exclusively in Python with the use of functions and objects as well as storing and tracking hydraulic states for control actions. In PySWMM step-wise execution, the hydraulic states (e.g., water depth and pipe flow) are collected as the inputs for control asset settings (e.g., orifice opening and gate positions), which are set before the next simulation step.

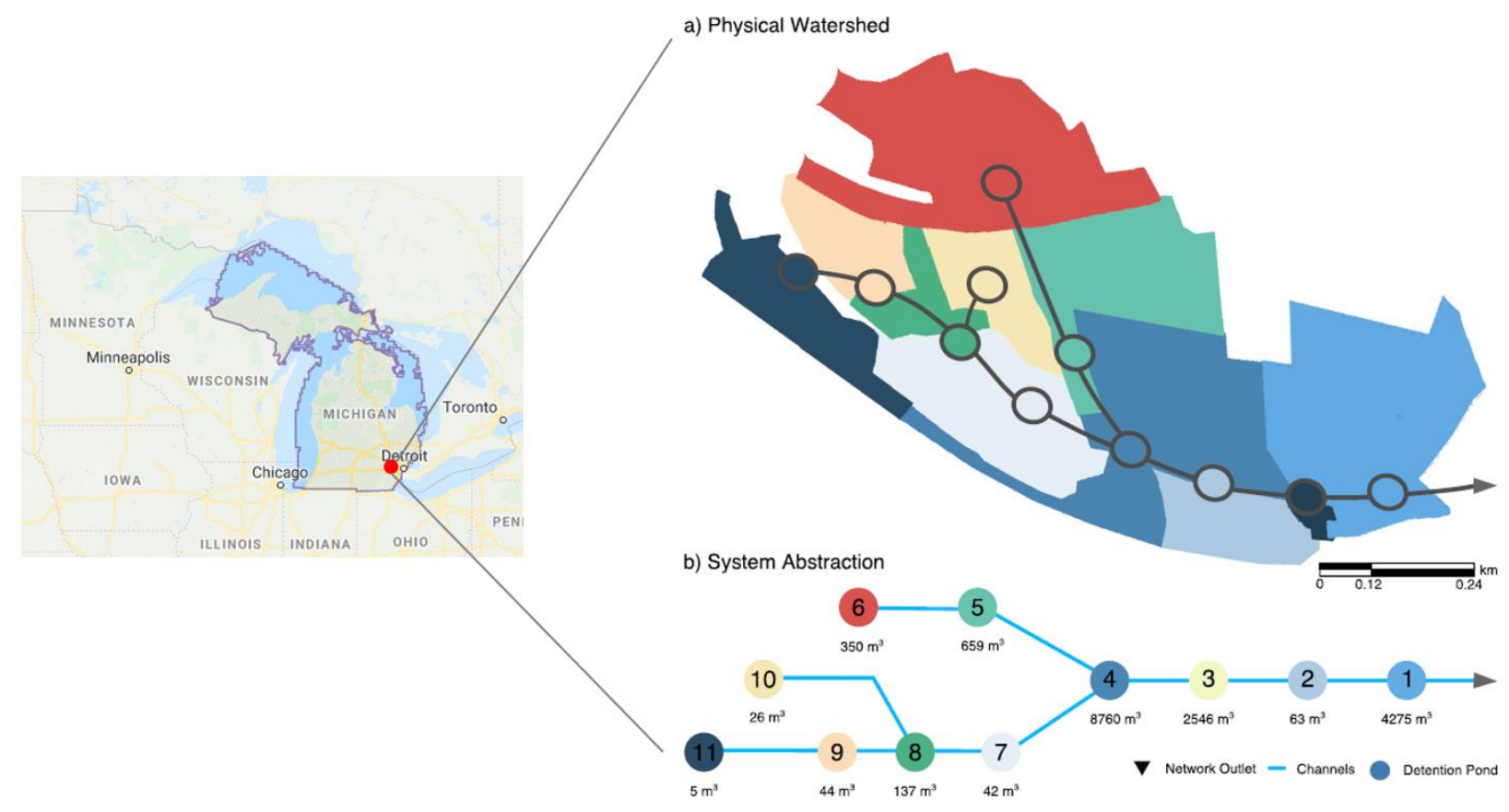

Fig. 1. The real-world, benchmarking gamma scenario SWMM model adopted from Mullapudi et al. (2020) (a presents the physical stormwater system being controlled; $\mathrm{b}$ demonstrates the volume capacity for storage units; $\mathrm{c}$ shows that the studied urban watershed is located in the southeast of Michigan State, USA).

\section{Methodology}


In this work, four control scenarios abbreviated as 'Baseline,' 'Downstream,' 'Sys_S,' and 'Sys_D' for baseline without control, the downstream individual control, system-level control with 11 same controllers, and system-level control with 11 different controllers, respectively, are conducted to assess the controller performance in mitigating flooding and improving water quality across the case study.

\subsection{Control strategy design}

In this paper, the control rule can be considered as a multi-linear function to characterize the relationship between storage water depth and orifice setting. Table 1 presents the rule-based correlation between actual water depth (AD) and the orifice setting, which is utilized for defining the controller. In this study, the baseline water depth (BD), threshold water depth (TD), and maximum water depth (MD) are determined according to the suggestions from Mullapudi et al. (2020). Controllers are used to determine the opening states of orifices during simulations. The control rules are set to reflect the controller's logic. These rules are:

Rule 1: If a rainfall event occurs, close the orifice gate and store the water to minimize the possibility of downstream flooding events, although it is still raining.

Rule 2: If the $\mathrm{AD}$ of the pond (storage unit) reaches the predefined $\mathrm{BD}$, keep the orifice gate closed until the flooding duration is decreasing at the downstream nodes.

Rule 3: If the $\mathrm{AD}$ of the pond is over the real TD, partially open the orifice gate to prevent overflow.

Rule 4: If the $\mathrm{AD}$ of the pond is over the predefined MD, open the sluice gate to full of limiting the flooding effects on the entire system. 
Rule 5: If the $\mathrm{AD}$ of the pond is controlled between $\mathrm{BD}$ and $\mathrm{TD}$, and also the runoff persists continuing, gradually open the orifice gate to cope with the incoming inflow and releasing outflow.

Rule 6: If the AD of the pond is controlled between the threshold and maximal water depth and the runoff continues, adjust the orifice gate opening at a system-level scale to reduce the nodal flooded duration.

Control rules are one of the components of control strategies, shown in Table 2. Table 2 presents the control strategies used in this study. In each control strategy, the control objects are the storage units being controlled. Actuators are the same as the orifices, and the targeting locations are the structures of interest.

Table 1. Relationship between water depth and orifice setting.

\begin{tabular}{|c|c|c|c|c|c|c|}
\hline Controller ID & Storage Unit ID & Orifice ID & BD (m) & TD (m) & MD (m) & Orifice Setting \\
\hline 1 & SU1 & OR39 & 0.78 & 2.00 & 2.91 & \\
\hline 2 & SU2 & OR34 & 0.78 & 2.30 & 2.91 & \\
\hline 3 & SU3 & OR44 & 0.78 & 2.00 & 2.91 & If $\mathrm{AD}<\mathrm{BD}$, close gate \\
\hline 4 & SU4 & OR45 & 0.78 & 2.30 & 2.76 & to $100 \%$ \\
\hline 5 & SU5 & OR38 & 0.78 & 2.00 & 2.47 & If $\mathrm{BD}<\mathrm{AD}<\mathrm{TD}$, open \\
\hline 6 & SU6 & OR46 & 0.78 & 2.00 & 2.47 & gate to $25 \%$ \\
\hline 7 & SU7 & OR48 & 0.10 & 2.00 & 2.76 & If $\mathrm{TD}<\mathrm{AD}<\mathrm{MD}$, open \\
\hline 8 & SU8 & OR47 & 0.78 & 2.00 & 2.61 & gate to $75 \%$; \\
\hline 9 & SU9 & OR36 & 0.78 & 2.00 & 2.61 & If $\mathrm{AD}>\mathrm{MD}$, open gate \\
\hline 10 & SU10 & OR43 & 0.78 & 2.00 & 2.47 & to $100 \%$. \\
\hline 11 & SU11 & OR35 & 1.39 & 2.00 & 2.47 & \\
\hline
\end{tabular}

Table 2. Control strategy designs. 


\begin{tabular}{|c|c|c|c|c|}
\hline Control strategy & Controlled objects & Actuators & Targeting location & $\begin{array}{l}\text { Rules used in this } \\
\text { control strategy }\end{array}$ \\
\hline 'Baseline' control & none & passive orifices & flooded nodes and all storage units & rule 1 \\
\hline 'Downstream' control & orifice OR1 & proactive orifice & downstream outlet and SU1 & rules $1,2,3$, and 5 \\
\hline 'Sys_S' control & all orifices & proactive orifices & flooded nodes and all storage units & rules $1,2,3,4$, and 5 \\
\hline 'Sys_D' control & all orifices & proactive orifices & flooded nodes and all storage units & rules $1,2,3,4,5$, and 6 \\
\hline
\end{tabular}

\subsection{Controller performance index}

Peak Depth Shaving Efficiency (PDSE) is the first indicator set for evaluating the performance of the real-time controller in reducing the peak depth of upstream storage units. The PDSE is computed using equation 1.

$$
\operatorname{PDSE}_{[i]}=\left(\frac{\text { Peak Depth }_{[i, b]}-\text { Peak Depth }_{[i, c]}}{\text { Peak Depth }_{[i, b]}}\right) \times \%
$$

Where $\operatorname{PDSE}_{[\mathrm{i}]}$ is the peak water depth shaving efficiency for the ith storage unit fraction [\%]; Peak Depth ${ }_{[i, b]}$ is the peak water depth for the ith storage unit under baseline simulation scenario $[\mathrm{m}]$; Peak Depth ${ }_{[i, c]}$ is the peak water depth for the ith storage unit under control simulation scenario $[\mathrm{m}]$.

Pollutant Removal Efficiency (PRE) is the second indicator set for evaluating the performance of the real-time controller in removing total suspended solids of upstream storage units. The PRE is computed using equation 2 .

$$
P R E_{[i]}=\left(\frac{T S S_{[i, b]}-T S S_{[i, c]}}{T S S_{[i, b]}}\right) \times \%
$$


Where $\mathrm{PRE}_{[\mathrm{i}]}$ is the pollutant removal efficiency for the ith orifice fraction [\%]; $\mathrm{TSS}_{[\mathrm{i}, \mathrm{b}]}$ is the load of TSS (Total Suspended Solids) for the ith orifice under the baseline simulation scenario [kg]; $\operatorname{TSS}_{[i, c]}$ is the load of TSS for the ith orifice under control simulation scenario [kg].

Flooded-hour Reduction (FR) is the third indicator set for evaluating the performance of the realtime controller in shortening the flooding duration of downstream nodes. The FR is computed using equation 3.

$$
F R_{[i]}=\text { Flooded Hour }_{[i, b]}-\text { Flooded Hour }_{[i, c]}
$$

Where $\mathrm{FR}_{[\mathrm{i}]}$ is the Flooded-hour Reduction for the ith flooded node [hour]; $\mathrm{FR}_{[\mathrm{i}, \mathrm{b}]}$ is the Flooded-

hour Reduction of the ith flooded node under baseline simulation scenario [hour]; $\mathrm{FR}_{[i, \mathrm{c}]}$ is the Flooded-hour Reduction of the ith flooded node under control simulation scenario [hour].

\section{Results}

\subsection{Understanding the time-series changes in orifice opening}

Fig.2 shows that temporal changes in control and hydraulic simulations, corresponding to storage unit SU1, under the rainfall events with an average $1.15 \mathrm{~mm} /$ hour intensity from $2014 / 07 / 05$ to 2014/07/07. This rainfall is chosen because it represents the average rainy year. According to Fig.2, there is no overflow under control scenarios that is better than the baseline scenario. All three control strategies close the orifice as inflow grows and then quickly open the orifice to $100 \%$ at the inflow hydrograph peaking time. One explanation for why the orifice opening suddenly jumps to $100 \%$ is because the water depth of SU1 is over the predefined Maximal water Depth (MD), so the system completely opens the orifice gate to prevent the upstream flooding severity, referring 
to rule 4 of section 3.1. In the initial period, the storage facility SU1 makes full use of volume to store inflow, according to rule 1. As the water level reaches the threshold water depth (TD), storage unit SU1 has to discharge the retained water into downstream pipes to avoid the local overflow or flooding based on the logic of rules 2 and 3. This process is consistent with the previous finding that system-level control has the ability to balance the upstream and downstream over-loadings (Troutman et al., 2020b). After that, the orifice opening decreases as the inflow hydrograph falls down. When the inflow gradually declines, the orifice opening keeps up-down for the final 12 hours and finally ends up with a 100\% opening. The reason why opening fluctuates frequently might be the water level remains between the threshold and maximal depth at this stage. Although the rain completely stops at the first 24 hours, the delay of runoff generation and concentration in the sub-catchments allows inflow to enter into the storage tank during the next 24 hours. As the rules 5 and 6 claims, the opening of orifice gates would be adjusted to adapt to the flow coming and releasing in the final stage, which causes the opening fluctuations in the final 12 hours of Fig.2. It can be seen that the increase or decrease in opening depends on the storage inflow, overflow, and outflow rate.

Compared with other flow patterns, the changes in outflow keep the same pace with orifice opening in these three control scenarios. Taking the Fig.2A as an example, we find that both orifice opening and tank outflow go down in the first 12 hours, followed by a significant increase, and then they gently decline between the second and third 12 hours, ending up with frequent up-down jumps in the fourth 12 hours. Changes in water depth are only in line with the orifice opening in the first 36 hours, although the water depth is linearly related to orifice opening. This comparison reveals that outflow may play a most important role than other hydraulic outputs (inflow, overflow, and water 
depth) in shaping the temporal changes in orifice opening under control scenarios. The same results are also captured in the storage units SU4 and SU9, shown in Fig 3 and 4, respectively.

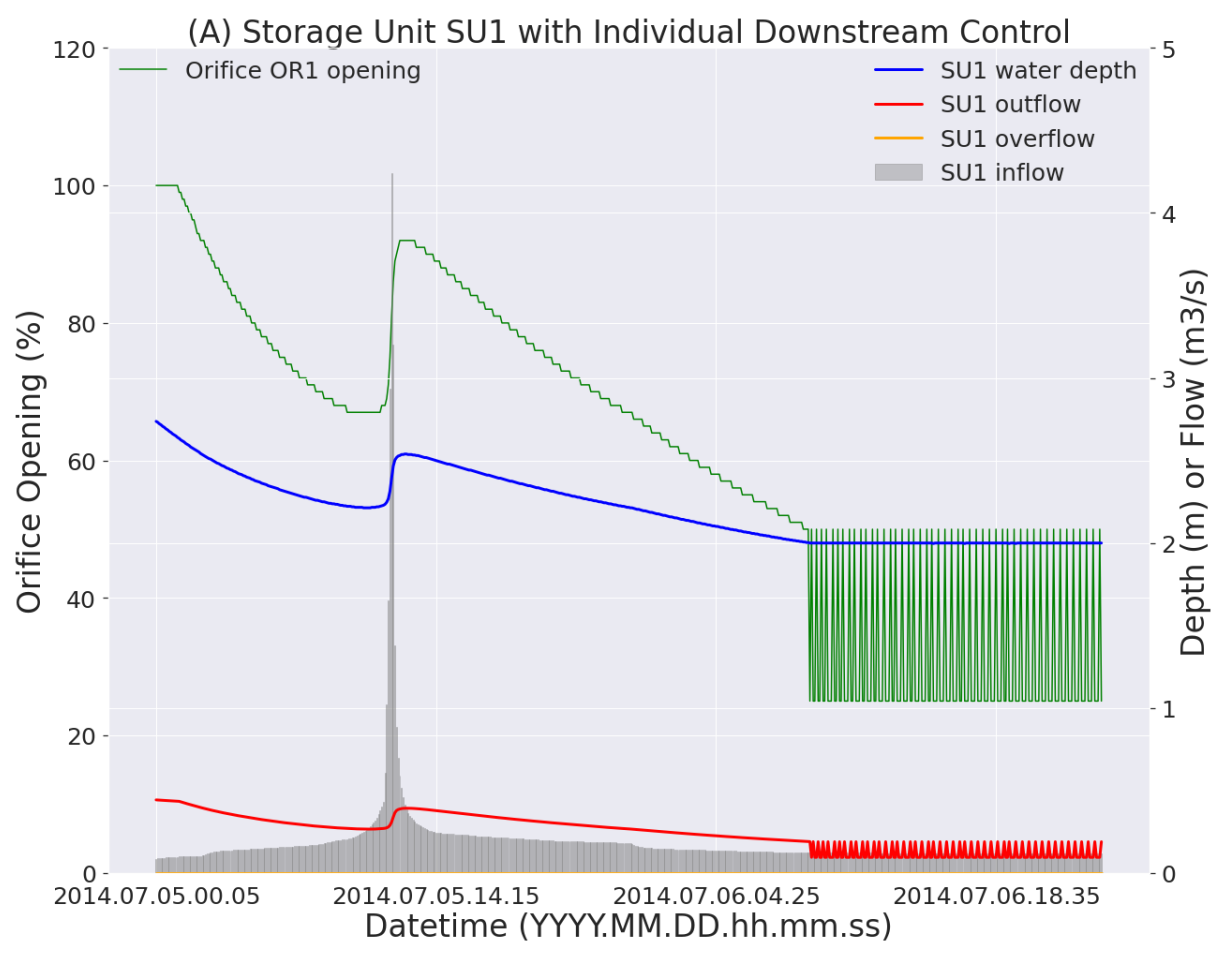

(A) 


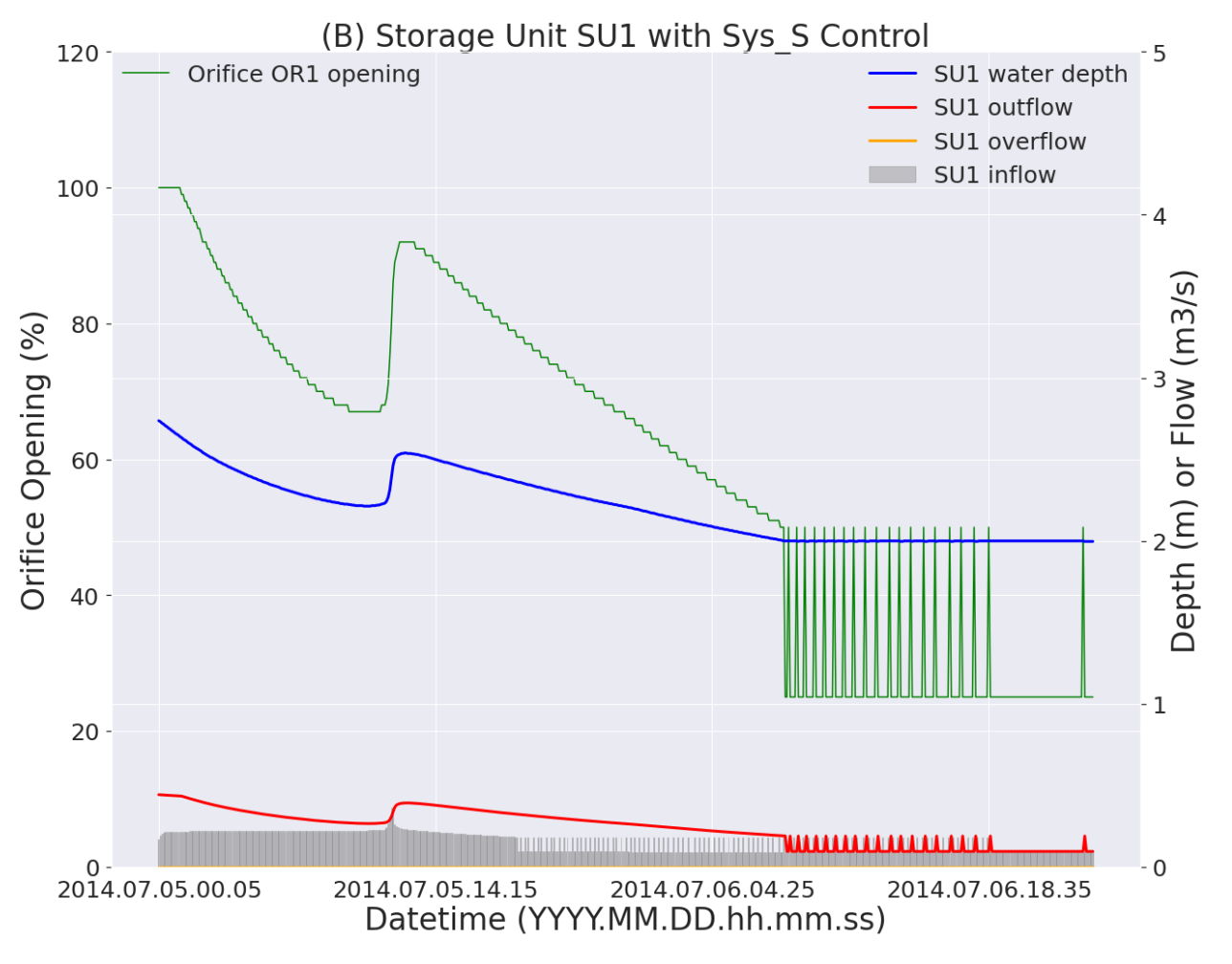

(B)

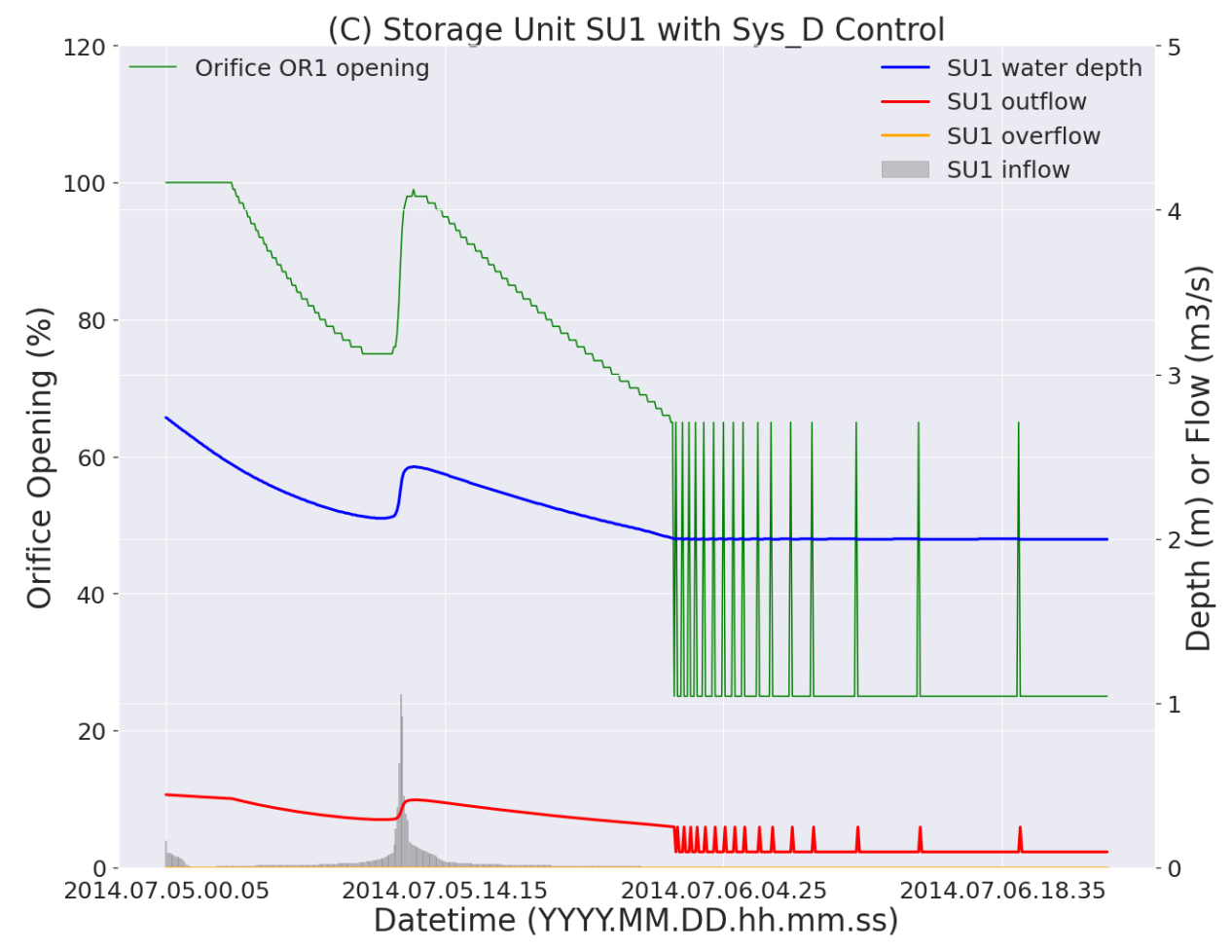


(C)

Fig. 2. Time-series plot of the openings for orifice OR1 (attached to storage unit SU1) on control scenarios: the most downstream control scenario ('Downstream', A), system-level control scenario with 11 same controllers ('Sys_S', B) system-level control scenario with 11 different controllers ('Sys_D', C).

SU4 and SU9 are selected to demonstrate the relationship between orifice opening and hydraulic storage changes. This selection is attributed to the evidence that SU4 and SU9 are representative storage assets for the downstream units with large size and upstream units with small size, respectively. According to Fig.3 and Fig.4, the 'Sys_D' control scenario shows a similar changing pattern to 'Sys_S' control scenario, while the orifice openings of the 'Sys_D' control scenario appear relatively larger and earlier for SU4 and SU9. Fewer fluctuations in orifice opening require less energy for actuator operation, indicating the control system is more stable in 'Downstream' and 'Sys_S' scenarios. Such gentle and steady operation in orifice is beneficial for avoiding abrupt actions and sudden opening of gates in practice. The orifice openings in the 'Sys_D' scenario require more energy, i.e., electricity supply, to operate, and system instability that may be magnified at the same point. This indicates that 'Sys_D' is more likely to result in wear on actuators.
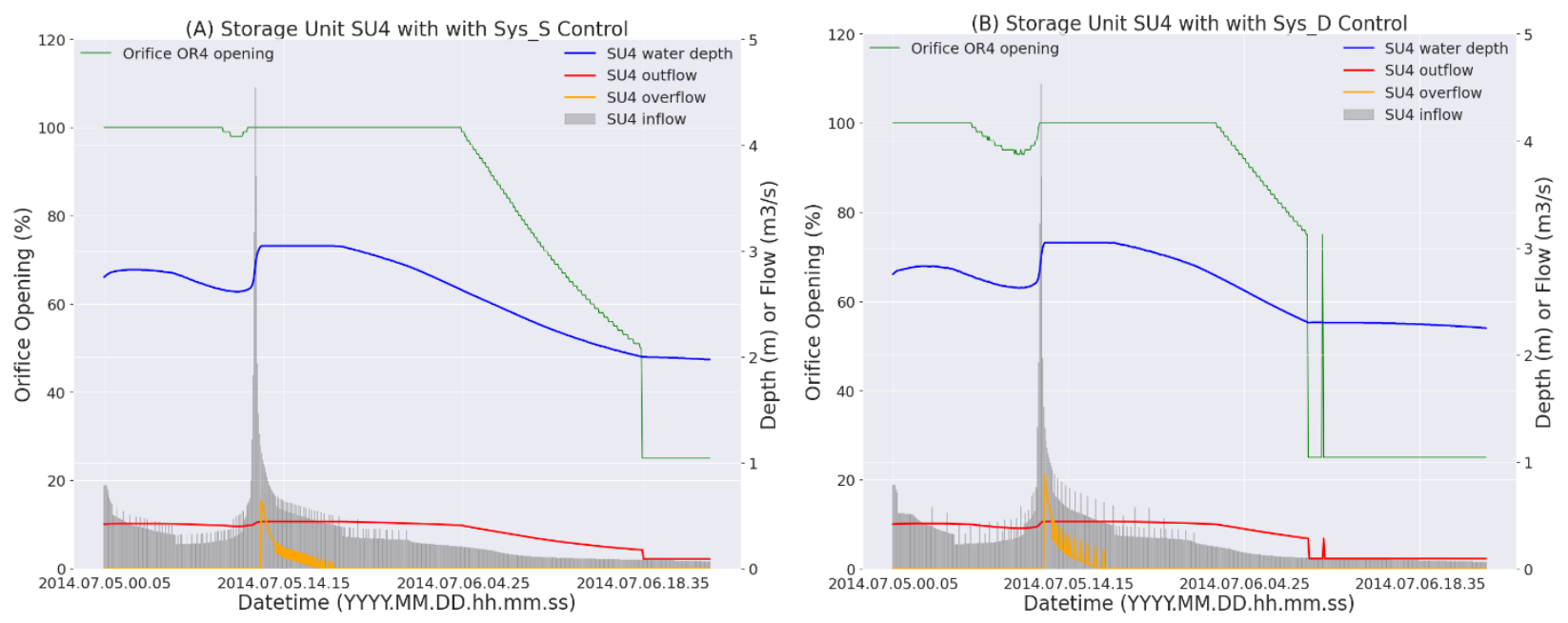
Fig. 3. Relating the orifice opening changes of OR4 to hydraulic changes of storage unit SU4 (SU4 is one of the representative downstream assets with small capacity) under control scenarios (A-'Sys_S'; B-‘Sys_D’).
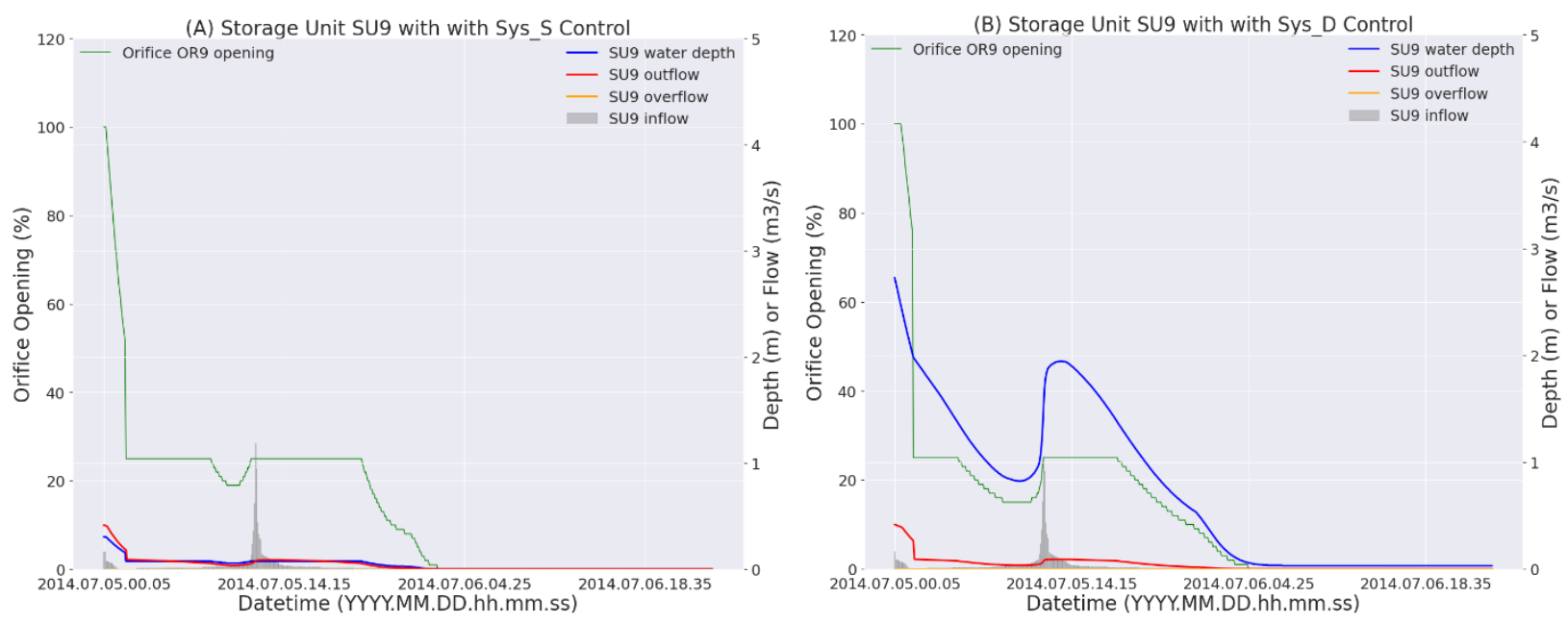

Fig. 4. Relating the orifice opening changes of OR9 to hydraulic changes of storage unit SU9 (SU9 is one of the representative upstream assets with small capacity) under control scenarios (A-‘Sys_S'; B-‘Sys_D’).

PySWMM can display control settings in a step-by-step style. As mentioned in section (2.3) of the methodology section, the open percentage dynamically adjusts itself based on the pre-set control rules for each orifice. Examples introduce above are three examples of the 11 storage units for discovering the pattern of continuous orifice open/close states at a step-wise simulation procedure. More spatial and temporal changes in the orifice opening of other 8 orifices are presented in Fig.S1 and Fig.S2 of supplementary materials for 'Sys_S' and 'Sys_D' scenarios, respectively. Spatially, each orifice senses the water level and then take actions step-by-step to prevent the local flooding and downstream water quantity and quality issues. These automatic adjustments offer researchers a fresh opportunity to gain an insight into how orifices can be controlled by real-time rules and adapt to the water quantity and quality changes. By better understanding how each orifice is adjusted, the setpoints for water quantity and quality objectives are supposed to be reached and maintained with the least number of operations. 


\subsection{Improving water quality by real-time control}

Fig.5 shows that the outcome of control is favorable compared to the uncontrolled baseline scenario, especially the system-level control scenarios for mitigating the TSS loadings. As we can see, over half of the TSS loading decrease when either the 'Sys_S' or Sys_D' control is implemented. In particular, the TSS loading of upstream storage facilities like SU8, 9, 10, and 11 noticeably declines. It can further be observed that the reduction magnitude of TSS loading on 'Sys_D' (with minimum $120.83 \mathrm{kgs}$ and maximum $137.39 \mathrm{kgs}$ ) is larger than that on the 'Sys_S' scenario (with minimum $91.39 \mathrm{kgs}$ and maximum $117.63 \mathrm{kgs}$ ). These results suggest that the 'Sys_D' control should be more capable of alleviating pollutant loads than the 'Sys_S' control. However, the amount of the TSS load under 'Downstream' control only has a slight decrease. For instance, there are only about $10 \mathrm{kgs}$ TSS drop from controlled to uncontrolled scenarios at the storage unit SU4.

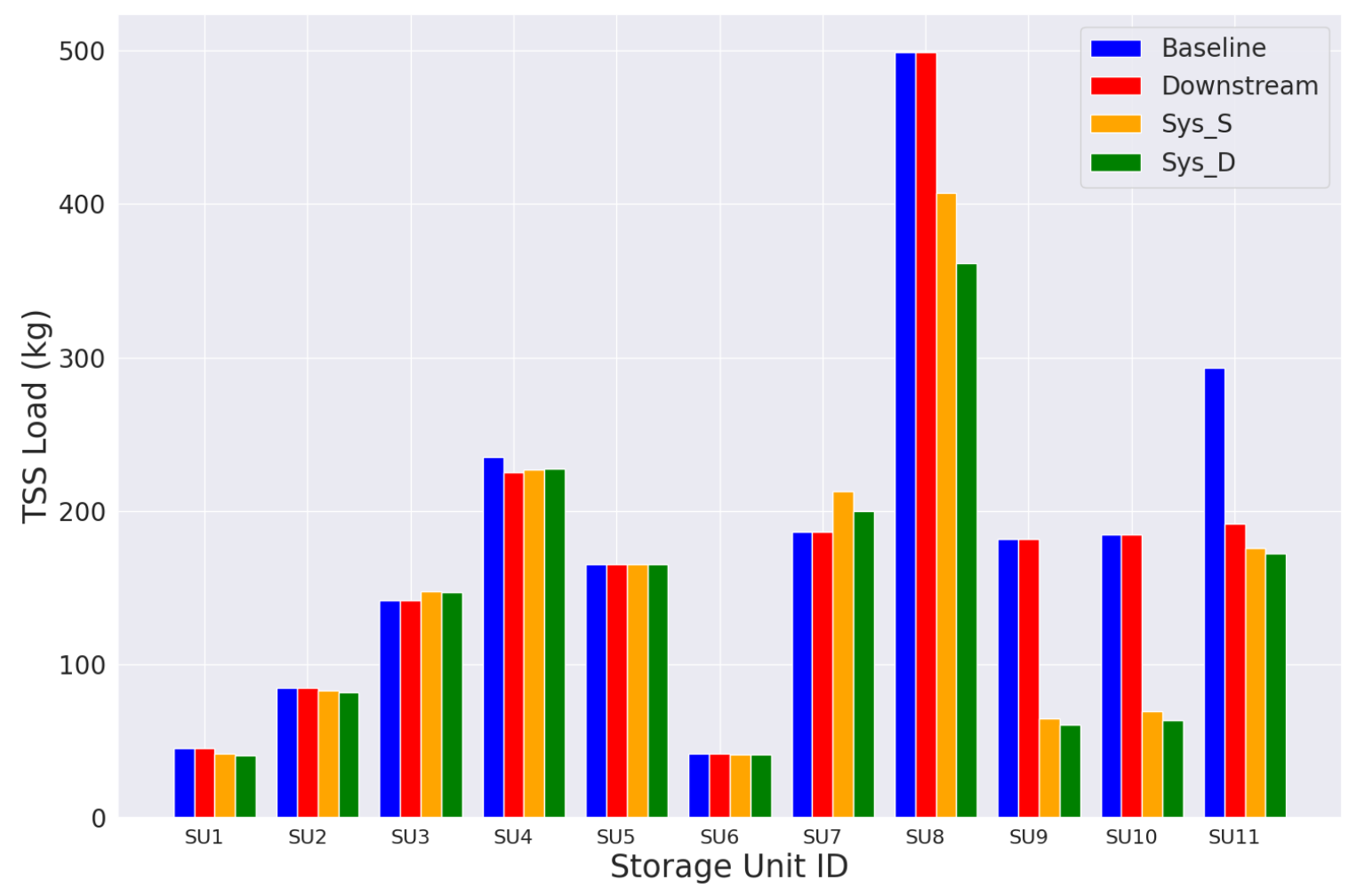


Fig. 5. Barplot of total suspended solids (TSS) load at storage units for cases with no control scenario ('Baseline'), the most downstream control scenario ('Downstream'), system-level control scenario with 11 same controllers ('Sys_S' ), system-level control scenario with 11 different controllers ('Sys_D'), and eleven controllers operated in coordination by these control strategies.

Fig.6 shows the boxplots of TSS concentration of SU4 and SU1 under different control scenarios. System controls have larger effects on squeezing the boxplots of SU4 and SU1 than local downstream control, with respect to the baseline scenario. As presented in Fig.1b, SU4 has the highest structural depth and the largest volume, which creates a substantially longer detention time than other storage units. The long detention time can be one of the reasons for making the TSS concentration of SU4 drop when controls are applied (Shishegar et al., 2019). As the second-largest assets, SU1 also shows a notable decrease in TSS due to the extended detention time in Fig.6. Additionally, SU1 is the most downstream storage unit (Fig.1b), and this location allows a longer traveling time that TSS needs to take before arriving at SU1 than at SU4. When to compare the TSS between SU1 and SU4, we further find that longer traveling time causes more significant reductions in mean and median TSS concentration from uncontrolled scenario to system-level controlled scenarios, The decrease of TSS can be attributed to the delay of TSS traveling from upstream to the downstream units (Carpenter et al., 2014). Taking the system remaining TSS loads as another water quality benefit, the downstream outlet, which receives TSS from SU1, produces the biggest TSS decrease with $41.36 \%$ under 'Sys_D,' followed closely by 'Sys_S' with 40.08\% TSS reduction (Fig.7). The individual 'Downstream' control has the least TSS decline percentage (34.71\%) in Fig.7. After comparison, the 'Sys_D' appears to be the best control strategy to maximize the benefits of TSS removal. 

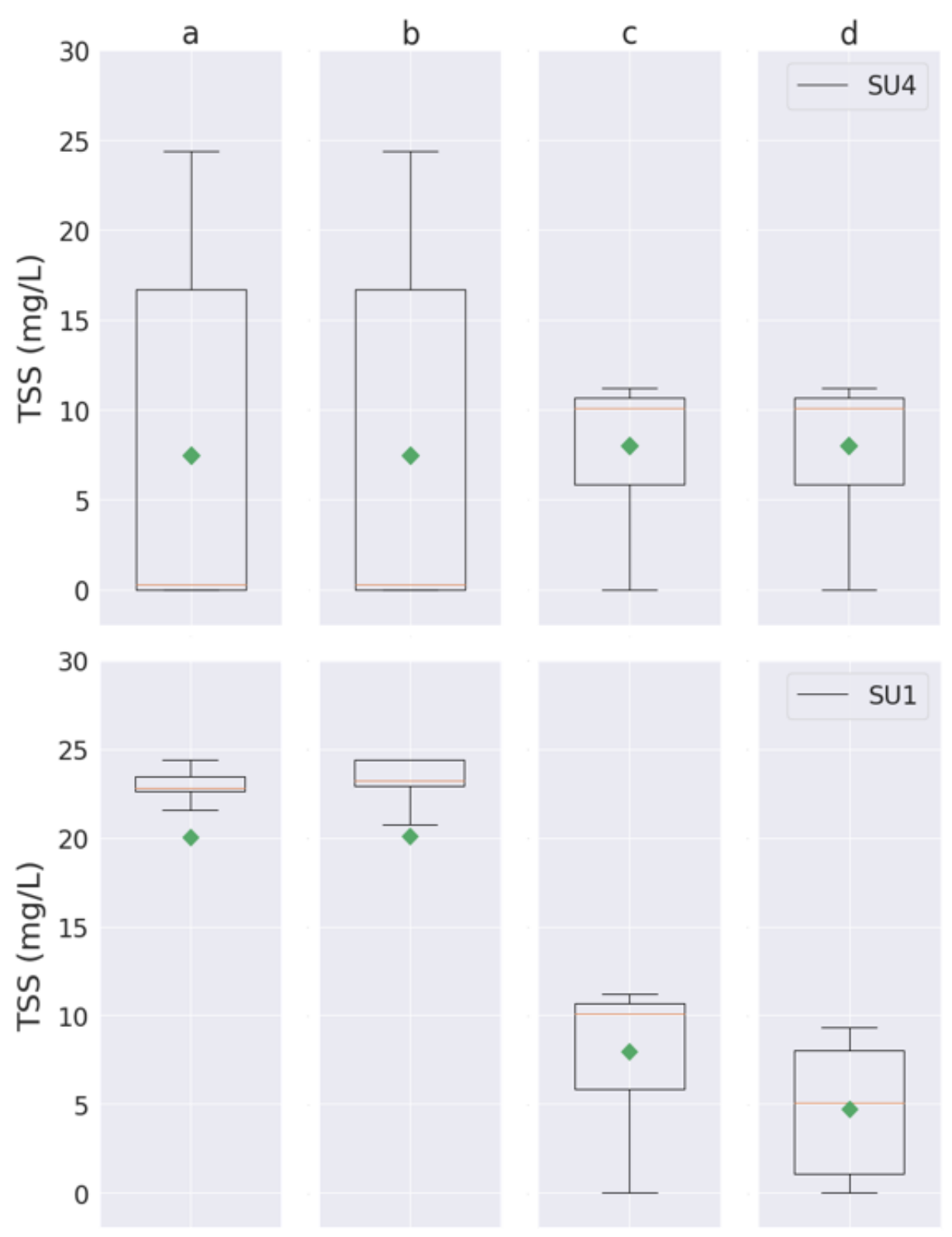

Fig. 6. Boxplot (green diamond is the mean and yellow line is the median) of Total suspended solids (TSS) concentration at the storage units SU4 and SU1 under a) no control ('Baseline,' the first boxplot), b) the most downstream control ('Downstream,' the second boxplot), c) system-level control with 11 same controllers ('Sys_S,' the third boxplot), and d) system-level control with 11 different controllers ('Sys_D,' the fourth boxplot). 


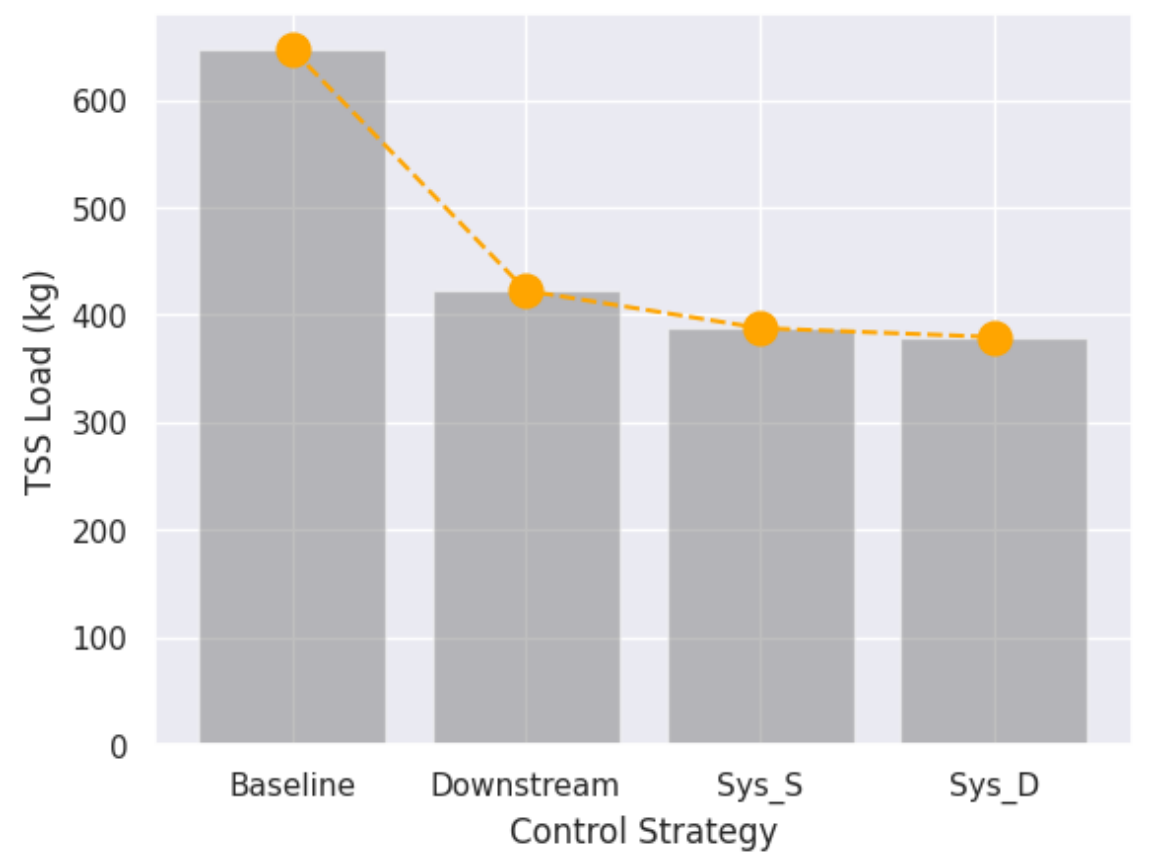

Fig. 7. Barplot of Total suspended solids (TSS) load at downstream outlet under three control scenarios including the no control ('Baseline' scenario), the most downstream control ('Downstream' scenario), system-level control with 11 same controllers ('Sys_S' scenario), and system-level control with 11 different controllers scenario ('Sys_D' scenario).

\subsection{Does system-level control always perform best?}

In this study, the comparisons between PDSE, PRE, and FR are used to evaluate the controller performance under different control strategies. Fig.8a shows that the largest PDSE belongs to the 'Sys_D' control scenario, on which the PDSE goes up to $7.30 \%$ at SU4. Conversely, the biggest PDSE at SU8 (5.13\%) and SU10 (3.20\%) occurs at the 'Downstream' control scenario. This difference reveals that the downstream controller has better performance in improving the downstream PDSE. The evidence from the PDSE comparison implies that the 'Downstream' control strategy has more ability to reduce the most downstream hydraulic stress than system-level control . 
The FR is employed to quantify the RTC capability of reducing flooding duration. A total number of 11 junctions (outlet, J2, J3, J4, J5, J6, J7, J8, J9, J10, J11), corresponding to the upstream storage units, are the targeted locations. Fig.8b demonstrates that controllers implemented at 'Sys_S' and 'Sys_D' strategy have significant FR values at nodes such as J2, J3, and J4; these nodes are located right after those downstream storage units (SU2, SU3, and SU4) with large storage volume in Fig.1. The largest flooding hour reductions happens at J2, where the FR value (34 hours) of the 'Sys_D' scenario is $54.84 \%$ higher than that (22 hours) of the 'Sys_S' scenario. In contrast, these upstream nodes from J5 to J11 only have slight decreases in the flooding duration. Nevertheless, the individual control makes the FR of the outlet, which is located on the most downstream junction, stand out from other scenarios in Fig.8b. The significant FR increase in outlet implies that individual control induces more effects than system-level control in pushing the downstream outlet away from flooding.

In the control strategy design of Table 3, system-level control is described as a trade-off between upstream storage capacity and downstream flooding mitigation. For example, if there is extreme rainfall, the gate would be closed, and water of the storage unit will slowly be discharged into the downstream flooded locations. However, if the gate is closed too much or remains closed too long, there will be overflow issues in upstream ponds. For instance, Fig.8b shows that $\mathrm{J} 9$ has negative reductions in flooding duration, which means that the control consequence has increased the flooding duration at junction J9. This phenomenon attributes to the non-optimal orifice action for opening the gate too long and ultimately leads to the downstream local flooding issues. In summary, the FR analysis above shows that the distributed system-level control outperforms individual 
downstream control in all flooded nodes, except for the outlet, whose FR of 'Downstream' control is higher than that of system-level control.

With regard to TSS removal, Fig.8c shows that there are few PRE differences between 'Sys_S' and 'Sys_D' situation, while they do provide larger PRE than 'Downstream' control. A positive PRE over $60 \%$ is found at 'Sys_S' and 'Sys_D' scenarios, close to other studies demonstrating a similar 65\% reduction (Gaborit et al., 2016, 2013a). In the 'Downstream' scenario, most of the PRE is below $10 \%$. The only PRE that reaches a comparable level (a level close to 'Sys_S' \& 'Sys_D' with around 40\% PRE ) is from the 'Downstream' controlled storage unit SU11 (35\% PRE), which is sited at the upstream watershed. This can be inferred that the downstream controller cannot behave as those system-level controllers for water quality improvement in most cases. Interestingly, we discover that the significant PDSE and FR mainly concentrate on the downstream storage units (SU1, 2, 3, and 4) with a large size, while the notable PRE comes from the upstream storage units (SU8, 9, 10, and 11) with a small size. This finding reflects that the size and location of storage units are related to the controller performance of reducing water quantity and quality over-loadings. System-level control provides favorable performance in hydraulic stress (PDSE and FR) reduction at downstream storage units with large volume capacity and in water quality improvement (PRE) at upstream storage units with small volume capacity. 


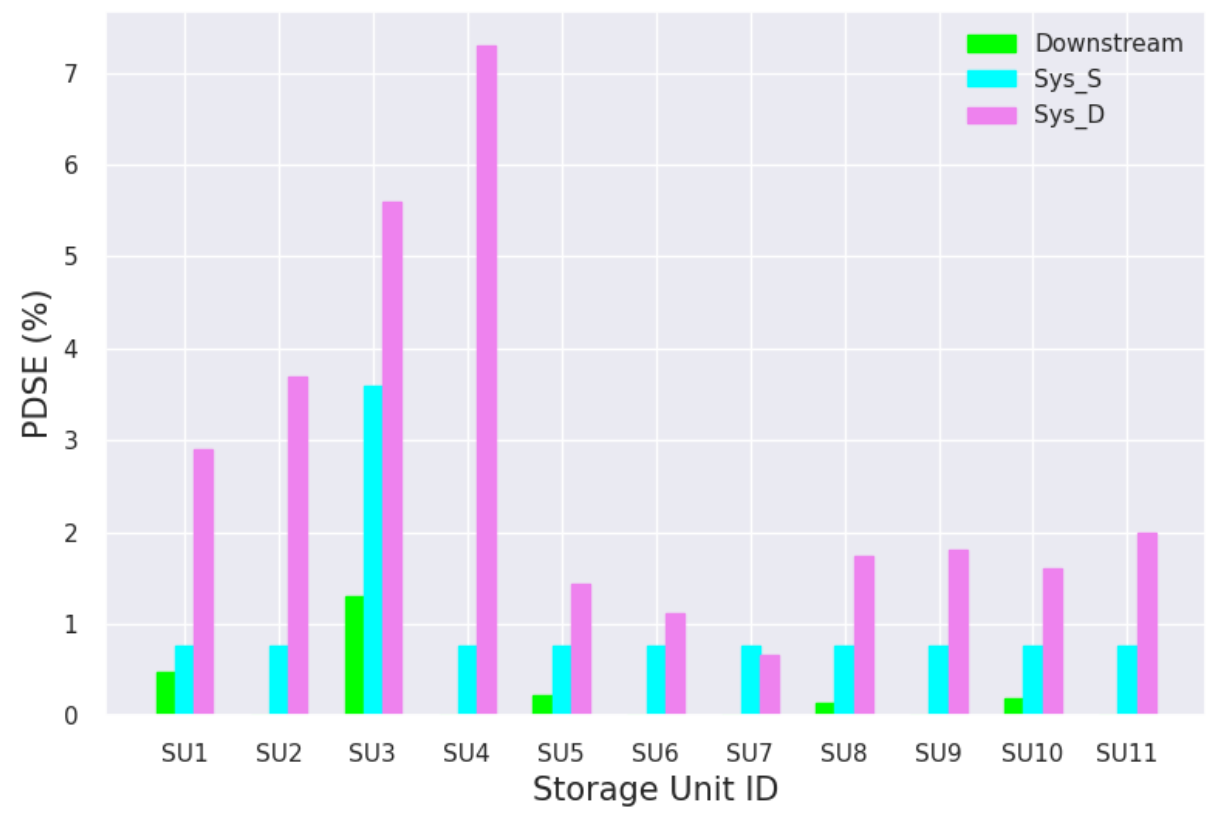

(a)

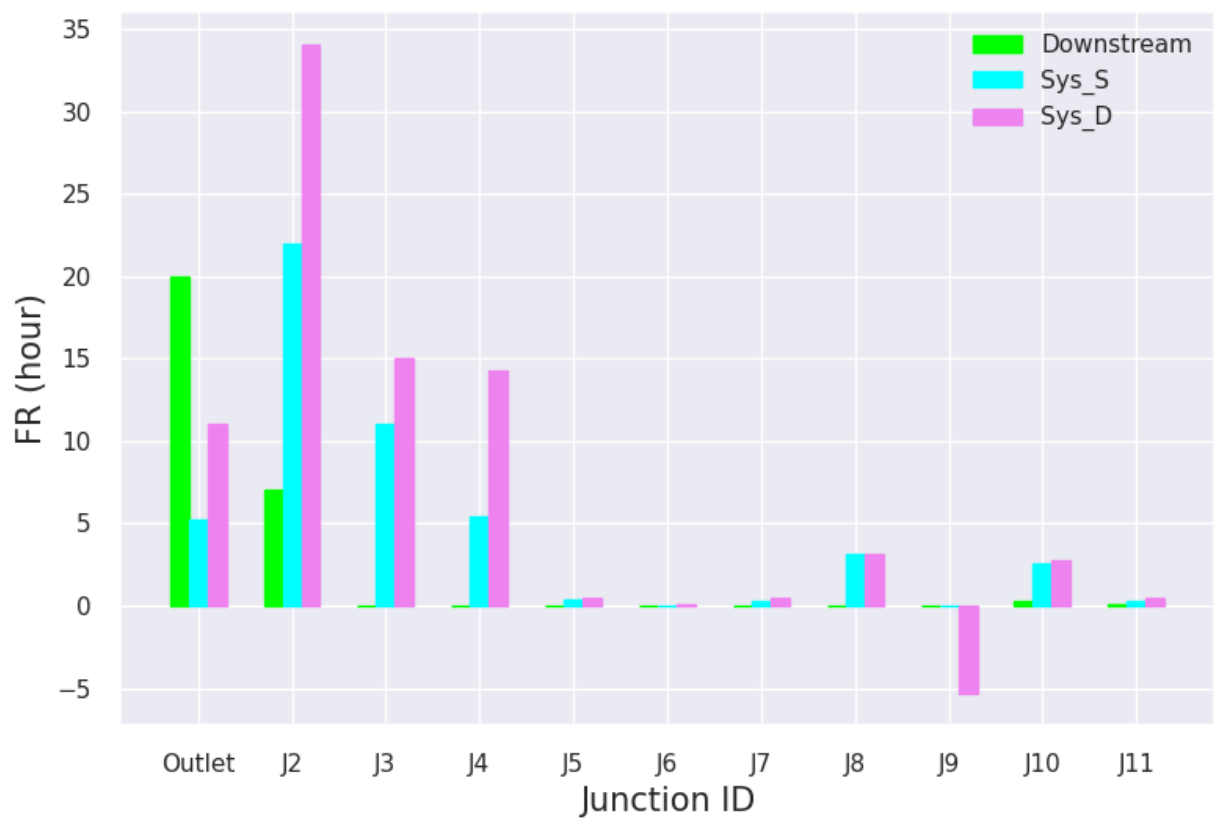

(b) 


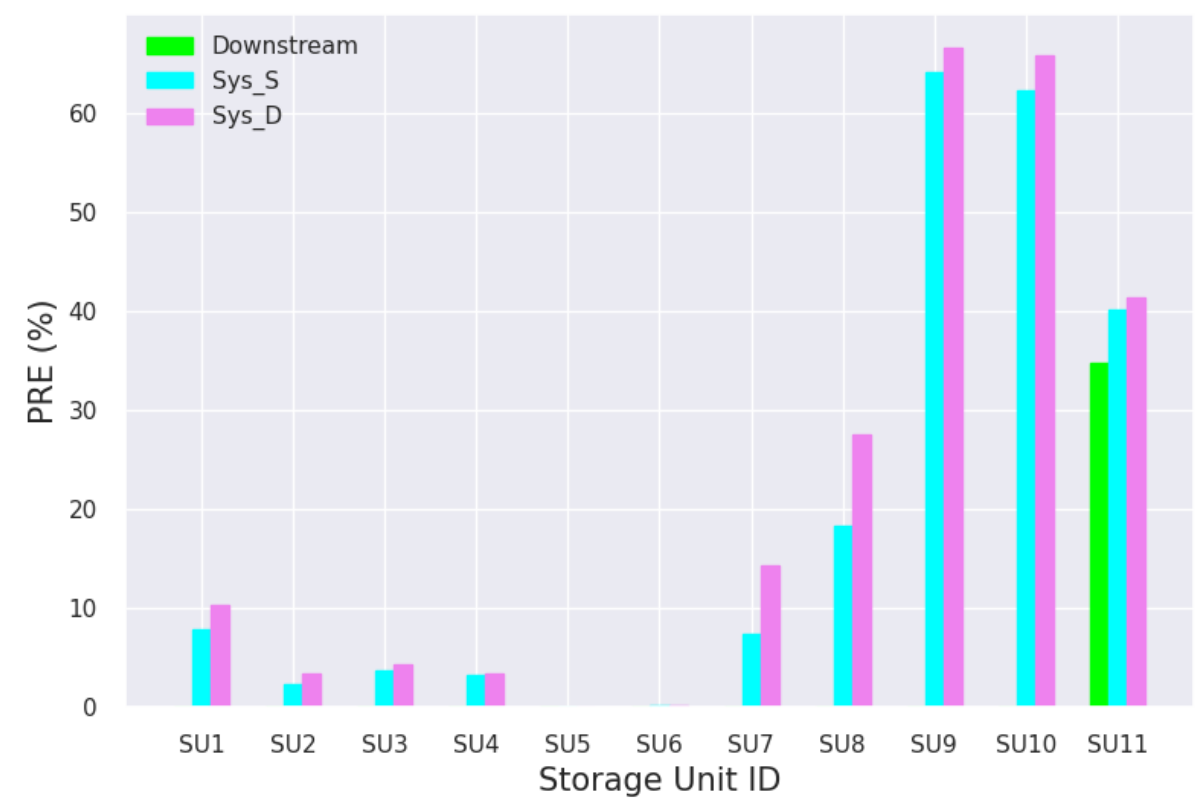

(c)

Fig. 8. Comparisons of (a) Peak Depth Shaving Efficiency (PDSE), (b) Flooded-hour Reduction (FR), (c) Pollutant Removal Efficiency (PRE) under control scenarios including the no control ('Baseline' scenario), the most downstream control ('Downstream' scenario), system-level control with 11 same controllers ('Sys_S' scenario), and system-level control with 11 different controllers scenario ('Sys_D' scenario).

\section{Discussions}

\subsection{Benefits of real-time control}

An open-source tool PySWMM is employed to develop and implement three rule-based RTC in this study. The performance of smart stormwater control strategies is evaluated for flooding mitigation and water quality improvements under the rainfall event. We make the codes of designing control strategies open to the public in this repository (https://github.com/Jiadalee/PyRTC), aimed to provide guidance for the smart stormwater participators who have expertise in stormwater management but no experience in real-time control work. 
The application of PySWMM to simulate the step-wide control logics provides insight into the functionalities and actions of smart stormwater RTC system. According to the visualization of time-series orifice opening, we can track the spatial and temporal changes in orifices and then classify their patterns for operation optimization, which can facilitate diminishing the risks of system abruptions, energy consumption, and costs (Rathnayake and Faisal Anwar, 2019). In our study, we find that the frequent control actions are mostly produced by the downstream orifices OR 2, 3, and 5 in Fig.S1 and Fig.S2, and a majority of full orifice openings occur at the inflow hydrograph peaking time (Fig.2 as an example). This discovery can lead the engineers and operators to identify the vulnerable sites before the flow peaks appear and then operate gates, valves, and pumps to avoid frequent operation and save laboring efforts in advance. Meanwhile, we examine that, instead of water depth, the tank outflow is an important indicator to characterize the system-level orifice temporal changes. Although this examination is not verified by fieldwork, it notes that flow-based control deserves investigation for improving controller performance.

The water quality modeling results show that the system-level control generally outperforms the individual 'Downstream' control in removing TSS. Previous studies show the maximum TSS removal efficiencies in stormwater storage basins ranging from 30\% to 75\% (Gaborit et al., 2013a; Mahmoodian et al., 2017; Sharior et al., 2019; Shishegar et al., 2019; Vezzaro et al., 2014). In our simulation experiments, the largest TSS removal efficiencies are 35\%, 63\%, and 66\% for 'Downstream', 'Sys_S', and 'Sys_D' controls, respectively. Thus, the developed rule-based control strategies in this study have similar performance in improving the water quality, compared with the previous researches above. 
In RTC performance assessment, we discover that the size and location of storage units are correlated to the controller performance. This discovery fills in the gap left from the prior study (Wong and Kerkez, 2018). The size of storage units, on the one hand, relates to the water depth, which is one of the popular input variables for most existing RTC algorithms (Di Matteo et al., 2019; Schütze et al., 2004). On the other hand, the size of storage volume determines how long the facilities can retain the water and identifies when the orifice gate should be open or closed. In watershed-scale control for multiple storage basins, the interactions between upstream and downstream sub-basins have potential influences on the RTC performance (Mullapudi et al., 2018). Thus, the location of storage units becomes an important factor in system-level RTC performance. For instance, the water discharged from the upstream storage basin will propagate to the downstream storage units, and therefore, not only the outflow can influence the orifice action, but also the inflow is anticipated to affect the orifice gate status. Schmitt et al. (2020) point out that RTC retrofitting may lead to increased peak flows, longer durations of flooding, and higher system instability without proper algorithm design and facility selection. Recognizing this point, we agree that the optimal controller size selection might also contribute to the desired performance of the system-level RTC (Wong and Kerkez, 2018).

\subsection{Limitations and future work}

This work is completed mainly based on co-simulating a ruled-based control strategy and rainfallrunoff process by using the open-source tool PySWMM. The first limitation of this study is the lack of fieldwork to verify modeled controllers' performance. Measurements and field testing in the future will play as a real-world testbed for the modeling outcomes in this paper. Secondly, the 
controller settings of the system-level control scenario in Table 2 were determined using a manual and experimental estimation, which is labor-intensive work. Online optimized control algorithms such as model predictive control (Lund et al., 2018) and fuzzy logic control (Li, 2020; Mounce et al., 2019) could be helpful for reducing the computational costs and improve control effectiveness.

Thirdly, it should be noticed that this water depth-based controller setting makes limited contributions to remove TSS concentration (Fig.6c). Although a real-time control strategy based on water depth of detention ponds could improve pollutant removal efficiency 40-90\% (Gaborit et al., 2016), it is arguable that the performance of hydraulic-dependent controllers to realize the water quality objectives varies from case to case (Ascott et al., 2016; Grayson et al., 1997; Sharma et al., 2016). Finally, forecasting information, such as rainfall forecasts, is ignored in this RTC work. Forecasts enable the RTC to flexibly and selectively discharge storm volume before extreme events; this allows UDSs to have more capacity to withstand threats and then adapt to future uncertainties (Gaborit et al., 2013b; Xu et al., 2020). There is room for future research to use observed and simulated precipitation sequences, perhaps in forecast mode, to sharpen the RTC performance.

\section{Summaries and conclusions}

Smart stormwater real-time control driven by rule-based logic shows promise to reduce the water quantity and quality over-loadings at system-wide watershed beyond the individual local control and uncontrolled system. In this study, we illustrate the design, implementation, and evaluation of system-level control to achieve multi-objective tasks, including peak depth shaving efficiency

(PDSE), pollutant removal efficiency (PRE), and flooded-hour reduction (FR), from upstream to 
downstream targeting sites. Our modeling experiments to co-simulate water quality and control strategy as a step-wise format are conducted based on the open-source tool PySWMM, a Python wrapper for Storm Water Management Model (SWMM). This co-simulation study highlights the importance of system-level real-time control to improve flooding mitigation and water quality improvements. In summary, conclusions are drawn below:

1) The use of the PySWMM tool to simulate rule-based real-time control strategies as a stepwise approach provides insight into how the system-level controller adjusts the gates by visualizing the spatial and temporal changes in orifice gate openings. The time-series adjustments in the orifice gate allow researchers and engineers to better understand how real-time control strategy automatically copes with the changes in water depth, outflow, and inflow, which can help local utilities to take early measures to prevent system instability and disruptions before extreme events occur. Particularly, the finding that storage unit outflow is an important predictor for the time-series changes of orifice opening indicates that the flow-based controller deserves more attention in the future.

2) Controller performance assessment shows that the system-level control outperforms the individual downstream control by obtaining PDSE up to 7\%, PRE up to 66\%, and FR up to $71 \%$ in this study. In contrast, the individual control strategy is more capable of reducing flooding duration in the downstream outlet. The differences in performance evaluation note that obtaining real-time control benefits depends on the objectives of decision-makers and also the preferences of stakeholders. Thus, designing the control strategies not only needs the optimal control rules but also is supposed to consider the human interests. 
3) We find that real-time control performance relates to the size and location of storage units. A relatively translatable rule is that the downstream controlled storage assets with large volume can significantly reduce the hydraulic stress, while the upstream controlled storage facilities with small volume can remove the total suspended solids favorably. This finding implies that the optimal design of urban stormwater collection systems, such as the storage site selection and storage capacity optimization, can improve the benefits in reducing water quantity and quality over-loadings.

4) All codes for developing rule-based real-time control are accessible to the public via https://github.com/Jiadalee/PyRTC. This open and straightforward real-time control implementation can be used for broader users to build complicated control strategies to meet their specific requirements from case to case, aimed to advance the progress of the smart stormwater community from theoretical to practical applications.

\section{Declaration of interests}

The authors declare that they have no known competing financial interests or personal relationships that could have appeared to influence the work reported in this paper.

\section{Acknowledgments}

We would like to thank Branko Kerkez and Brandon Wong, who is from the real-time water system group of the University of Michigan, for sharing the relevant model and files.

\section{References}


Abou Rjeily, Y., Abbas, O., Sadek, M., Shahrour, I., Hage Chehade, F., 2018. Model Predictive Control for optimising the operation of Urban Drainage Systems. Journal of Hydrology 566, 558-565. https://doi.org/10.1016/j.jhydrol.2018.09.044

Ascott, M.J., Lapworth, D.J., Gooddy, D.C., Sage, R.C., Karapanos, I., 2016. Impacts of extreme flooding on riverbank filtration water quality. Science of the Total Environment. https://doi.org/10.1016/j.scitotenv.2016.02.169

Berggren, K., Olofsson, M., Viklander, M., Svensson, G., Gustafsson, A.-M., 2012. Hydraulic Impacts on Urban Drainage Systems due to Changes in Rainfall Caused by Climatic Change. Journal of Hydrologic Engineering 17, 92-98. https://doi.org/10.1061/(ASCE)HE.1943-5584.0000406

Bilodeau, K., Pelletier, G., Duchesne, S., 2018. Real-time control of stormwater detention basins as an adaptation measure in mid-size cities. Urban Water Journal 15, 858-867. https://doi.org/10.1080/1573062X.2019.1574844

Campisano, A., Cabot Ple, J., Muschalla, D., Pleau, M., Vanrolleghem, P.A., 2013. Potential and limitations of modern equipment for real time control of urban wastewater systems. Urban Water Journal. https://doi.org/10.1080/1573062X.2013.763996

Carpenter, J.F., Vallet, B., Pelletier, G., Lessard, P., Vanrolleghem, P.A., 2014. Pollutant removal efficiency of a retrofitted stormwater detention pond. Water Quality Research Journal of Canada. https://doi.org/10.2166/wqrjc.2013.020

Casal-Campos, A., Fu, G., Butler, D., Moore, A., 2015. An Integrated Environmental Assessment of Green and Gray Infrastructure Strategies for Robust Decision Making. Environmental Science and Technology 49, 8307-8314. https://doi.org/10.1021/es506144f

Chiang, P.K., Willems, P., 2015. Combine Evolutionary Optimization with Model Predictive Control in Real-time Flood Control of a River System. Water Resources Management 29, 2527-2542. https://doi.org/10.1007/s11269-015-0955-5

Creaco, E., Campisano, A., Fontana, N., Marini, G., Page, P.R., Walski, T., 2019. Real time control of water distribution networks: A state-of-the-art review. Water Research. https://doi.org/10.1016/j.watres.2019.06.025

Di Matteo, M., Liang, R., Maier, H.R., Thyer, M.A., Simpson, A.R., Dandy, G.C., Ernst, B., 2019. Controlling rainwater storage as a system: An opportunity to reduce urban flood peaks for rare, long duration storms. Environmental Modelling and Software. https://doi.org/10.1016/j.envsoft.2018.09.020

Gaborit, E., Anctil, F., Pelletier, G., Vanrolleghem, P.A., 2016. Exploring forecast-based management strategies for stormwater detention ponds. Urban Water Journal 13, 841-851. https://doi.org/10.1080/1573062X.2015.1057172

Gaborit, E., Muschalla, D., Vallet, B., Vanrolleghem, P.A., Anctil, F., 2013a. Improving the performance of stormwater detention basins by real-time control using rainfall forecasts. Urban Water Journal. https://doi.org/10.1080/1573062X.2012.726229

Gaborit, E., Muschalla, D., Vallet, B., Vanrolleghem, P.A., Anctil, F., 2013b. Improving the performance of stormwater detention basins by real-time control using rainfall forecasts. Urban Water Journal 10, 230-246. https://doi.org/10.1080/1573062X.2012.726229 
Giordano, A., Spezzano, G., Vinci, A., Garofalo, G., Piro, P., 2014. A Cyber-Physical System for Distributed RealTime Control of Urban Drainage Networks in Smart Cities. pp. 87-98. https://doi.org/10.1007/978-3-31911692-1_8

Grayson, R.B., Gippel, C.J., Finlayson, B.L., Hart, B.T., 1997. Catchment-wide impacts on water quality: The use of "snapshot" sampling during stable flow. Journal of Hydrology. https://doi.org/10.1016/S0022-1694(96)032751

Heusch, S., Ostrowski, M., 2015. Model Predictive Control with SWMM. Journal of Water Management Modeling. https://doi.org/10.14796/jwmm.r241-14

HRWC, 2013. Malletts creekshed report [WWW Document]. URL https://www.hrwc.org/wpcontent/uploads/Malletts_8x11.5.pdf (accessed 5.15.19).

Kerkez, B., Gruden, C., Lewis, M., Montestruque, L., Quigley, M., Wong, B., Bedig, A., Kertesz, R., Braun, T., Cadwalader, O., Poresky, A., Pak, C., 2016. Smarter stormwater systems. Environmental Science and Technology. https://doi.org/10.1021/acs.est.5b05870

Kroll, S., Fenu, A., Wambecq, T., Weemaes, M., Van Impe, J., Willems, P., 2018. Energy optimization of the urban drainage system by integrated real-time control during wet and dry weather conditions. Urban Water Journal 15, 362-370. https://doi.org/10.1080/1573062X.2018.1480726

Li, J., Yang, X., Sitzenfrei, R., 2020. Rethinking the Framework of Smart Water System: A Review. Water (Switzerland) 12(2), 412.

Li, J., 2020. A data-driven improved fuzzy logic control optimization-simulation tool for reducing flooding volume at downstream urban drainage systems. Science of the Total Environment 732, 138931. https://doi.org/10.1016/j.scitotenv.2020.138931

Li, J., Burian, S., Oroza, C., 2019a. Exploring the potential for simulating system-level controlled smart stormwater system, in: World Environmental and Water Resources Congress 2019: Water, Wastewater, and Stormwater; Urban Water Resources; and Municipal Water Infrastructure - Selected Papers from the World Environmental and Water Resources Congress 2019.

Li, J., Tao, T., Kreidler, M., Burian, S., Yan, H., 2019b. Construction Cost-Based Effectiveness Analysis of Green and Grey Infrastructure in Controlling Flood Inundation: A Case Study. Journal of Water Management Modeling. https://doi.org/10.14796/jwmm.c466

Löwe, R., Vezzaro, L., Mikkelsen, P.S., Grum, M., Madsen, H., 2016. Probabilistic runoff volume forecasting in riskbased optimization for RTC of urban drainage systems. Environmental Modelling and Software 80, 143-158. https://doi.org/10.1016/j.envsoft.2016.02.027

Lund, N.S.V., Borup, M., Madsen, H., Mark, O., Arnbjerg-Nielsen, K., Mikkelsen, P.S., 2019. Integrated stormwater inflow control for sewers and green structures in urban landscapes. Nature Sustainability. https://doi.org/10.1038/s41893-019-0392-1

Lund, N.S.V., Falk, A.K.V., Borup, M., Madsen, H., Steen Mikkelsen, P., 2018. Model predictive control of urban drainage systems: A review and perspective towards smart real-time water management. Critical Reviews in Environmental Science and Technology. https://doi.org/10.1080/10643389.2018.1455484 
Mahmoodian, M., Delmont, O., Schutz, G., 2017. Pollution-based model predictive control of combined sewer networks, considering uncertainty propagation. International Journal of Sustainable Development and Planning. https://doi.org/10.2495/SDP-V12-N1-98-111

McDonnell, B., Ratliff, K., Tryby, M., Wu, J., Mullapudi, A., 2020. PySWMM: The Python Interface to Stormwater Management Model (SWMM). Journal of Open Source Software. https://doi.org/10.21105/joss.02292

Meng, F., Fu, G., Butler, D., 2020. Regulatory Implications of Integrated Real-Time Control Technology under Environmental Uncertainty. https://doi.org/10.1021/acs.est.9b05106

Mollerup, A.L., Mikkelsen, P.S., Thornberg, D., Sin, G., 2017. Controlling sewer systems-a critical review based on systems in three EU cities. Urban Water Journal 14, 435-442. https://doi.org/10.1080/1573062X.2016.1148183

Mounce, S.R., Shepherd, W., Ostojin, S., Abdel-Aal, M., Schellart, A.N.A., Shucksmith, J.D., Tait, S.J., 2019. Optimisation of a fuzzy logic-based local real-time control system for mitigation of sewer flooding using genetic algorithms. Journal of Hydroinformatics. https://doi.org/10.2166/hydro.2019.058

Mullapudi, A., Bartos, M., Wong, B., Kerkez, B., 2018. Shaping streamflow using a real-time stormwater control network. Sensors (Switzerland). https://doi.org/10.3390/s18072259

Mullapudi, A., Lewis, M.J., Gruden, C.L., n.d. Deep Reinforcement Learning for the Real Time Control of Stormwater Systems.

Mullapudi, A., Lewis, M.J., Gruden, C.L., Kerkez, B., 2020. Deep reinforcement learning for the real time control of stormwater systems. Advances in Water Resources 140. https://doi.org/10.1016/j.advwatres.2020.103600

Mullapudi, A., Wong, B.P., Kerkez, B., 2017. Emerging investigators series: Building a theory for smart stormwater systems. Environmental Science: Water Research and Technology. https://doi.org/10.1039/c6ew00211k

Muschalla, D., Vallet, B., Anctil, F., Lessard, P., Pelletier, G., Vanrolleghem, P.A., 2014a. Ecohydraulic-driven realtime control of stormwater basins. Journal of Hydrology. https://doi.org/10.1016/j.jhydrol.2014.01.002

Muschalla, D., Vallet, B., Anctil, F., Lessard, P., Pelletier, G., Vanrolleghem, P.A., 2014b. Ecohydraulic-driven realtime control of stormwater basins. Journal of Hydrology. https://doi.org/10.1016/j.jhydrol.2014.01.002

Parolari, A.J., Pelrine, S., Bartlett, M.S., 2018. Stochastic water balance dynamics of passive and controlled stormwater basins. Advances in Water Resources 122, 328-339. https://doi.org/10.1016/j.advwatres.2018.10.016

Rathnayake, U., Faisal Anwar, A.H.M., 2019. Dynamic control of urban sewer systems to reduce combined sewer overflows and their adverse impacts. Journal of Hydrology. https://doi.org/10.1016/j.jhydrol.2019.124150

Riaño-Briceño, G., Barreiro-Gomez, J., Ramirez-Jaime, A., Quijano, N., Ocampo-Martinez, C., 2016. MatSWMM An open-source toolbox for designing real-time control of urban drainage systems. Environmental Modelling and Software 83, 143-154. https://doi.org/10.1016/j.envsoft.2016.05.009

Rimer, S.P., Troutman, S.C., Mullapudi, A., Kerkez, B., 2019. Demo abstract: A benchmarking framework for control and optimization of smart stormwater networks, in: ICCPS 2019 - Proceedings of the 2019 ACM/IEEE International Conference on Cyber-Physical Systems. https://doi.org/10.1145/3302509.3313336

Rossman, L.A., 2015. STORM WATER MANAGEMENT MODEL USER'S MANUAL Version 5.1. EPA/600/R14/413b, National Risk Management Laboratory Office of Research and Development. United States 
Environmental Protection Agency, Cincinnati, Ohio.

Ruggaber, T.P., Talley, J.W., Montestruque, L.A., 2007. Using embedded sensor networks to monitor, control, and reduce CSO events: A pilot study. Environmental Engineering Science. https://doi.org/10.1089/ees.2006.0041

Sadler, J.M., Goodall, J.L., Behl, M., Bowes, B.D., Morsy, M.M., 2020. Exploring real-time control of stormwater systems for mitigating flood risk due to sea level rise. Journal of Hydrology. https://doi.org/10.1016/j.jhydrol.2020.124571

Sadler, J.M., Goodall, J.L., Behl, M., Morsy, M.M., Culver, T., Bowes, B.D., 2019. Leveraging open source software and parallel computing for model predictive control of urban drainage systems using EPA-SWMM5. Environmental Modelling \& Software. https://doi.org/10.1016/j.envsoft.2019.07.009

Schmitt, T.G., Thomas, M., Ettrich, N., 2004. Analysis and modeling of flooding in urban drainage systems. Journal of Hydrology 299, 300-311. https://doi.org/10.1016/S0022-1694(04)00374-9

Schmitt, Z.K., Hodges, C.C., Dymond, R.L., 2020. Simulation and assessment of long-term stormwater basin performance under real-time control retrofits. Urban Water Journal. https://doi.org/10.1080/1573062X.2020.1764062

Schütze, M., Campisano, A., Colas, H., Schilling, W., Vanrolleghem, P.A., 2004. Real time control of urban wastewater systems - Where do we stand today? Journal of Hydrology. https://doi.org/10.1016/j.jhydrol.2004.08.010

Sharior, S., McDonald, W., Parolari, A.J., 2019. Improved reliability of stormwater detention basin performance through water quality data-informed real-time control. Journal of Hydrology. https://doi.org/10.1016/j.jhydrol.2019.03.012

Sharma, A.K., Vezzaro, L., Birch, H., Arnbjerg-Nielsen, K., Mikkelsen, P.S., 2016. Effect of climate change on stormwater runoff characteristics and treatment efficiencies of stormwater retention ponds: a case study from Denmark using TSS and Cu as indicator pollutants. SpringerPlus. https://doi.org/10.1186/s40064-016-3103-7

Shishegar, S., Duchesne, S., Pelletier, G., 2019. An Integrated Optimization and Rule-based Approach for Predictive Real Time Control of Urban Stormwater Management Systems. Journal of Hydrology. https://doi.org/10.1016/j.jhydrol.2019.124000

Stevens, M., 2012. Cities and Flooding: A Guide to Integrated Urban Flood Risk Management for the 21st Century by Abhas Jha, Robin Bloch, Jessica Lamond, and other contributors. Journal of Regional Science. https://doi.org/10.1111/jors.12006_6

Sun, C., Puig, V., Cembrano, G., 2020. Real-time control of urban water cycle under cyber-physical systems framework. Water (Switzerland). https://doi.org/10.3390/w12020406

Troutman, S.C., Love, N.G., Kerkez, B., 2020a. Balancing water quality and flows in combined sewer systems using real-time control. Environmental Science: Water Research \& Technology. https://doi.org/10.1039/c9ew00882a

Troutman, S.C., Love, N.G., Kerkez, B., 2020b. Balancing water quality and flows in combined sewer systems using real-time control. Environmental Science: Water Research and Technology 6, 1357-1369. https://doi.org/10.1039/c9ew00882a

Vezzaro, L., Christensen, M.L., Thirsing, C., Grum, M., Mikkelsen, P.S., 2014. Water quality-based real time control 
of integrated urban drainage systems: A preliminary study from Copenhagen, Denmark. Procedia Engineering 70, 1707-1716. https://doi.org/10.1016/j.proeng.2014.02.188

Vezzaro, L., Grum, M., 2014. A generalised Dynamic Overflow Risk Assessment (DORA) for Real Time Control of urban drainage systems. Journal of Hydrology. https://doi.org/10.1016/j.jhydrol.2014.05.019

Waters, D., Watt, W.E., Marsalek, J., Anderson, B.C., 2003. Adaptation of a storm drainage system to accomodate increased rainfall resulting from climate change. Journal of Environmental Planning and Management 46, 755770. https://doi.org/10.1080/0964056032000138472

Wong, B.P., Kerkez, B., 2018. Real-Time Control of Urban Headwater Catchments Through Linear Feedback: Performance, Analysis, and Site Selection. Water Resources Research. https://doi.org/10.1029/2018WR022657

Xu, W.D., Fletcher, T.D., Burns, M.J., Cherqui, F., 2020. Real-Time Control of Rainwater Harvesting Systems: The Benefits of Increasing Rainfall Forecast Window. Water Resources Research 0-2. https://doi.org/10.1029/2020WR027856

Zhang, P., Cai, Y., Wang, J., 2018. A simulation-based real-time control system for reducing urban runoff pollution through a stormwater storage tank. Journal of Cleaner Production. https://doi.org/10.1016/j.jclepro.2018.02.130 